\title{
LOS ASPECTOS AFECTIVO-EMOCIONALES EN LAS TEORÍAS IMPLÍCITAS. CONDICIONES, PROCESOS Y RESULTADOS EN LA ENSEÑANZA-APRENDIZAJE
}

\author{
Gustavo Daniel Beláustegui \\ Pontificia Universidad Católica Argentina
}

\section{INTRODUCCIÓN}

Se pretende destacar la importancia de la dinámica de las emociones y la afectividad' en las teorías implícitas que manejan tanto los docentes como los aprendices con el objeto de proponer técnicas de conocimiento interpersonal y sus valores, promoviendo la preparación y reflexión de los docentes para tal fin. Se consideran de modo especial los aportes de Sastre Vilarrasa y Moreno Marimon (2003) en tanto material técnico-didáctico para el trabajo en el aula, sin entrar en el contenido de los mismos. La conceptualización general de Wellman, sobre los modelos cognitivos, permite ensamblar constructos tanto motivacionales ( Nuttin, J., 1980) como de unidades de análisis intrapsicológicas. Estos sistemas explicativos permitirán sostener las orientaciones de los cambios requeridos en las prácticas de las currículas académicas, para integrar los descubrimientos de las habilidades de conocimiento interpersonales en los adolescentes en concreto, sin descuidar la perspectiva unificadora de una Psicología General y del Desarrollo.

\section{UNA REVOLUCIÓN NECESARIA PARA LAS CONDICIONES DEL APRENDIZAJE: LA PERSPECTIVA INTERPERSONAL}

El descubrimiento del propio estilo interpersonal, que se busca generar en los alumnos, es un desafío que interpela en primera instancia al docente que es invitado a trabajar con este tipo de tareas, no sin la sorpresa ante tal actividad inusual. Dadas estas circunstancias, no debe dejarse de lado la necesidad de considerar la naturaleza de este tipo de conocimiento, cuya particularidad exige una ambientación especial en la organización educativa, donde el clima propicio, producto del encuentro convergente entre la organización formal e informal ( Petit, F., 1979), se hace realidad. Es por esto que estas tareas de intervención interpersonal, precisan estar familiarizadas, mo solo desde un conocimiento técnico, sino vivencial de los miembros de la organización educativa. También se requiere el apoyo institucional a través de la currícula, que solo puede iniciarse desde la toma de conciencia y aceptación por los miembros de las organizaciones educativas. Un instrumento valioso para este fin es la implementación de los Grupos GREC ( véase Barreiro, T., 1992) como un medio de autoconocimiento, previo por cierto, a cualquier implementación de alguna de las técnicas de conocimiento afectivo-emocional (Sastre Vilarrasa; Moreno Marimon, 2003). Para esta implementación, es fundamental poseer un marco teórico sólido, que oriente la práctica, permitiendo integrar un actualizado y vigoroso conocimiento científico interdisciplinario. Los valiosos aportes de Howard Gradner $(1985,1993)$ sobre la inteligencia personal, servirían en este caso, como marco para organizar la didáctica orientada al descubrimiento de estos aspectos tan sutiles y difíciles de manejar. Aspectos, que surgen de la relación entre la conciencia y las unidades afectivoemocionales propias y ajenas; Gardner (1985) escribe: 
La capacidad medular que opera aquí es el acceso a la propia vida sentimental, la gama propia de afectos o emociones: la capacidad para efectuar al instante discriminaciones entre los sentimientos, y con el tiempo, darles nombre, desenredarlos en códigos simbólicos, de utilizarlos como un modo de comprender y guiar la conducta propia. En esta forma primitiva, la inteligencia interpersonal es apenas poco más que la capacidad de distinguir un sentido de placer de uno de dolor...En un nivel más avanzado... permite descubrir y simbolizar conjuntos complejos y altamente diferenciados de sentimientos....La otra inteligencia personal se vuelve al exterior, hacia otros individuos. Aquí, la capacidad medular es la habilidad para notar y establecer distinciones entre otros individuos y, en particular, entre sus estados de ánimo, temperamentos, motivaciones e intenciones. (p. 288).

Ahora, cabe preguntarse sobre si es necesario para educar sobre la autopercepción interpersonal, la implementación o no de un dispositivo educativo interpersonal, o simplemente se requiere la preparación y capacitación del docente. Sastre Vilarrasa y Moreno Marimon (2003) proponen la intervención a través de técnicas complejas, pero descuidan la preparación emocional, tan delicada, para estas tareas. Si se tiene en cuenta tanto la técnica en sí como la preparación de quienes las implementen, se estarán evitando aplicaciones destructivas, no solo para el alumno y el docente, sino para la organización educativa misma. Un emprendimiento de esta naturaleza requerirá de una modificación de los sistemas organizacionales relacionales - como también en el orden institucional mismo - normas y objetivos-.

Estas prácticas, si pretenden implementarse, traerán consigo una reestructuración de las Teorías de Dominios ( Pozo, J. I. Scheuer, N.2000) intersubjetivos o interpersonales (Gardner, H. 1993) - si se permite la adjetivación-, que implica de suyo un cambio conceptual de las Teorías implícitas, de los alumnos y docentes al mismo tiempo. Por cierto, manejarse con estos temas no parece tan sencillo, no solo por la tarea en sí, sino también por la ausencia de tradición en la mayoría de las organizaciones educativas. Las prácticas de esta didáctica interpersonal requerirían, para su implementación adecuada, una orientación desde un enfoque constructivista. Este se justifica por la importancia de la valoración individual de la propia conciencia y sus contenidos, que se ve acrecentada en la particular subjetividad de la etapa adolescente. Es imprescindible, por lo tanto, una preparación del docente para la ayuda y acompañamiento de los estudiantes, y un asesoramiento profesional psicológico para evaluar el curso de estos acontecimientos en caso de problemas que puedan suscitarse. Otra cuestión de suma importancia es la consideración de la modalidad para presentar estas intervenciones. Estas precisarían ser acercadas al adolescente como tarea cuya evaluación solo puede estar a cargo de la intimidad de cada uno, y marcando las limitaciones relativas, asegurando la relatividad del alcance de la técnica, cuya naturaleza solo es la de exploración facilitadora del autoconocimiento personal. Eh aquí donde esta perspectiva, en tanto método semejante a la mayéutica socrática, se dispone como una herramienta valiosa en la educación de un sujeto en formación.

\section{LA ETAPA CRÍTICA: FERTILIDAD DE LOS VALORES}

Desprendimiento del pasado y realización progresiva, dos notas de la etapa crítica adolescente, donde el trabajo de la interioridad, de la introspección fructífera, toma un relieve particular, como no se da en otra etapa del desarrollo. Louise Kaplan en la introducción del libro "Adolescencia, El adiós a la infancia”, expresa esta realidad única:

Más que el nacimiento, el matrimonio y la muerte, la adolescencia implica el complejísimo drama de pasar de una zona de la existencia a otra distinta. Es ese punto crítico de la vida humana en que las pasiones sexuales y morales fructifican y alcanzan su madurez....Aunque es posible que ellos se sorprendan tanto como sus padres y sus maestros al escucharlo, los adolescentes, esas criaturas patéticamente susceptibles y vulnerables, apasionadas e impulsivas, totalmente sexuales y monstruosamente egocéntricas, son, en realidad, ávidos buscadores de autenticidad moral. Por encima de todo, desean lograr algún poder efectivo sobre el mundo en que viven y al mismo tiempo permanecer fieles a sus valores e ideales. (p. 11) 
Es en esta calidad de drama donde aparece esta poderosa necesidad de alcanzar "un poder efectivo sobre el mundo", es aquí justamente donde el sistema educativo debería intervenir en esta orientación intersubjetiva. Los valores y los ideales se hacen aliados insustituibles de una estrategia que pueda prometer el descubrimiento del sí-mismo como puerta para advertir y conocer a los otros significativos. Con el objeto de acompañarlos, para quebrar con las ataduras del pasado y capitalizarlas para mirar y enfrentar el futuro, no debe sin embargo llevárseles a olvidar, sino a una participación de la memoria activa. La misma autora afirma:

Una explosión de crecimiento impulsa al adolescente hacia el futuro. Una ola de fresca vitalidad que expande cada uno de sus apetitos e intereses franqueará las estructuras del pasado, abriendo el camino a nuevas soluciones. Pese a estas fuerzas inexorables que lo empujan hacia adelante, a lo que habrá de ser, el adolescente se ve al mismo tiempo arrastrado hacia a tras, a lo que fue un tiempo. ( p. 101)

Situar esta realidad permite orientar sobre el uso de un sin número de herramientas didácticas dirigidas a la intervención integral, no en un docente aislado, sino en una comunidad educativa despierta a estas realidades. Puede generarse, gracias al aporte de un marco teórico pertinente, una reflexiva y productiva investigación-acción, que acompañe a la práctica y afiance estas novedosas perspectivas. John Elliott en el prólogo al libro de Mc Kernan expone de modo sintético la tarea cooperativa que se propone en este trabajo, donde reflexión y cambios eficientes se sostienen mutuamente:

El desarrollo profesional del profesor por medio de la práctica reflexiva es desde luego una dimensión importante de la investigación-acción, como McKernan muestra en el Capítulo II. Sin embargo, evita el autor abstraer esta dimensión del contexto del currículum, del que ha surgido la investigación-acción educativa. Mc Kernan y para mí, el propósito de hacer investigación-acción como profesor es lograr cambios que valgan la pena educativamente, y hay consideraciones de currículo y de pedagogía en el núcleo de esta empresa.( $p$. 19)

Esta práctica reflexiva sobre una sistematización adecuada de los datos enmarca a las técnicas que pueden utilizarse, no en simples dispositivos esporádicos, sino en verdaderos eslabones que coayuden a un cambio de paradigma en la educación y en especial en el cambio conceptual de las teorías implícitas de los docentes en primer término. Esta se convertirá en una empresa donde la afectividad y emocionalidad se orienten a los valores morales y sociales, sin los cuales no puede construirse la convivencia de una sociedad tolerante de las diferencias culturales y religiosas.

Volviendo a la implementación de estas valiosas herramientas, queda destacar la importancia de la concepción sistémica. Esta permitirá articular el marco para poder interpretar adecuadamente las intervenciones aquí reflexionadas, dado que las consideraciones de la causalidad lineal de la interpretación del comportamiento, llevaría a un fragmentación de la actividad y un uso parcial de ellas. Esta concepción de las relaciones interpersonales se impone como necesaria para explicitarla dentro de una Teoría general de la personalidad, distinguiéndose de los usados por la Psicología dinámica en la educación. Esta última, sesga la capacidad reorganizativa de los sistemas de agrupamientos que son tan importantes en la Psicología de la Educación. A su vez, téngase en cuenta la importancia de la Familia en la afectividad humana y más aún en la etapa adolescente. Las palabras claves de Interacción y Sistema podría constituirse en guía para orientar los resultados a través de estos procesos particulares que se proponen aquí. Es necesario, sin embargo, que los docentes y directivos tengan en cuenta la naturaleza de la motivación implicada, esto es, su dimensión relacional y sistémica, para una adecuada percepción de las condiciones de los aprendices. 


\section{MOTIVACIÓN: UN ORGANIZADOR PARA LA ACCIÓN}

Para Nuttin "la motivación concierne a la dirección activa de la conducta hacia categorías preferenciales de situaciones o de objetos“( p. 13). De aquí se desprenden dos problemas, uno en relación a los objetos hacia los cuales se dirige y por otro los procesos que intervienen en el funcionamiento de la motivación. En el primero tenemos el contenido, en el segundo los mecanismos. Se pretende que esta perspectiva integre tanto los spectos cognitivos y emocionales como también lo hace Vygostky en relación a un funcionamiento total del individuo. Esta integración se puede observar en toda la obra del autor, considerando la cabalgadura de lo psicológico y lo biológico, advirtiendo que la naturaleza relacional de la motivación ya está en el funcionamiento biológico mismo.

Así la perspectiva que se defiende aquí, quiere no dejar de lado la actividad biológica y sus funciones en la explicación del comportamiento. Si se sigue a Nuttin (1980), se presentan tres vías de interacción que dispone el individuo humano: el de manipulación física de los objetos, el contacto cognitivo y la interacción social. Ahora bien esta capacidad de interrelación social es importante para comprender la naturaleza de las Representaciones Sociales que se encuentran como condiciones para el proceso del cambio conceptual nombrado. Nuttin iii (1980) afirma:

Lo que da al contacto interpersonal su naturaleza específica es la función afectiva - yendo del amor al odio- así como la reciprocidad ... Más aún, la posibilidad de expresar a otros ideas y sentimientos personales y de registrar su respuesta, viene a completar esta forma especial de interacción...La diversidad cualitativa de las motivaciones es grande en el seno del contacto intersonal. (p. 106 )

Esta reciprocidad percibida podría considerarse como uno de los puntos orientativos más significativos para la construcción de un marco común en este tipo de intervenciones educativas de la subjetividad humana. Este concepto de reciprocidad percibida se ve amplificado por el de autovalía personal ( Covington y Beery, 1976; Convington, 1992), pivote estratégico para tener siempre en cuenta la necesidad de preservar la autoestima del alumno en cuestión, y por cierto del docente mismo. Motivación, metas y autoestima están sobre el mismo eje compartido en la relación experto-novato, aunque aquí la relación no parezca ser tan asimétrica y clara como en el conocimiento explicito de las ciencias particulares. Cuidar la autovalía de las partes recíprocas - tanto del alumno como del docente- podría se un logro no tan fácil de alcanzar. En términos de Martín Covington:

... la teoría de la valía personal sostiene, en esencia, que, desde el punto de vista psicológico, el logro escolar se comprende mejor en términos de mantener una imagen personal positiva de la propia capacidad, sobre todo cuando se corre el peligro de fracasar en un entorno competitivo. ( $p$ 82)

Sobre este punto, Scheuer y Pozo, al referirse a las Teoría implícitas del docente, dan cuenta de la realidad de proteger ese sentimiento de ser capaz, que no es otra cosa que reconocer la autovalía personal :

Cuando de lo que se trata es de ayudar a los alumnos a aprender, los profesores reconocen la importancia del trabajo y el esfuerzo y, en consecuencia, recompensan el valor y la energía. Pero cuando el centro de atención se desplaza del aprendizaje en sí mismo a predecir qué alumnos tienen más probabilidades de tener éxito en empleos de prestigio, los profesores valoran la capacidad como el factor más importante (Kaplan y Swant, 1973). Esta distinción entre capacidad como elemento de predicción de futuro éxito laboral y el esfuerzo como ingrediente necesario para aprender no pasa desapercibida a los alumnos y los pone en cruel aprieto. A pesar de los innegables beneficios del esfuerzo, se enfrentan a una necesidad que compite con él: la de proteger sus sentimientos de ser competente. ( p. 83)

\section{MODELO DEL RAZONAMIENTO DE CREENCIAS- DESEOS}

La conceptualización realizada por Wellman -ya nombrada en la introducción- de la unidad de análisis creencia-deseo constituye un modelo explicativo de la interacción de la afectividad-emoción en los 
procesos cognitivos permitiendo explicar ciertas teorías implícitas (Pozo, J. I. 2000). El planteo desde el control de las acciones permite enmarca estos desarrollos en una implementación de las tomas de decisiones ( en el aula y en las organizaciones educativas). El modelo expresado gráficamente por Wellman en sus dos versiones enriquece las posibilidades de compresión de la dinámica del sí-mismo en tanto que le otorga una perspectiva en la psicología del desarrollo o evolutiva. ( pp. 113, 122).

Los conceptos nucleares y vínculos que presenta el autor permiten presentar una "cartografía..-iv con el objeto de delimitar territorios para el acceso a la matriz afectivo-emocional a través de métodos didácticos que puedan incluirse en la Currícula Académica, similares a los usados por Genoveva Sastre Vilarrasa y Montserrat Moreno Marimon (2003). Por otro lado este mapa permite al docente una visión íntegra del funcionamiento del sí-mismo para re-actualiazar la visión del proceso enseñanza y aprendizaje. Tenemos aquí conceptos potentes para poder armar una teoría explícita que pueda se reflexiva en la actividad docente y enriquecida por tareas y técnicas para la investigación acción.

\section{GRAFICO 1}

\section{Esquema simplificado para describir el razonamiento de la creencia-deseo de Wellman y Bartch (1988)}

- creer, suponer

- saber, esperar

- dudar, sospechar

- ver, oir, oler

-tocar, subir

PERCEPCIÓN CREENCIA

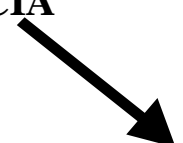

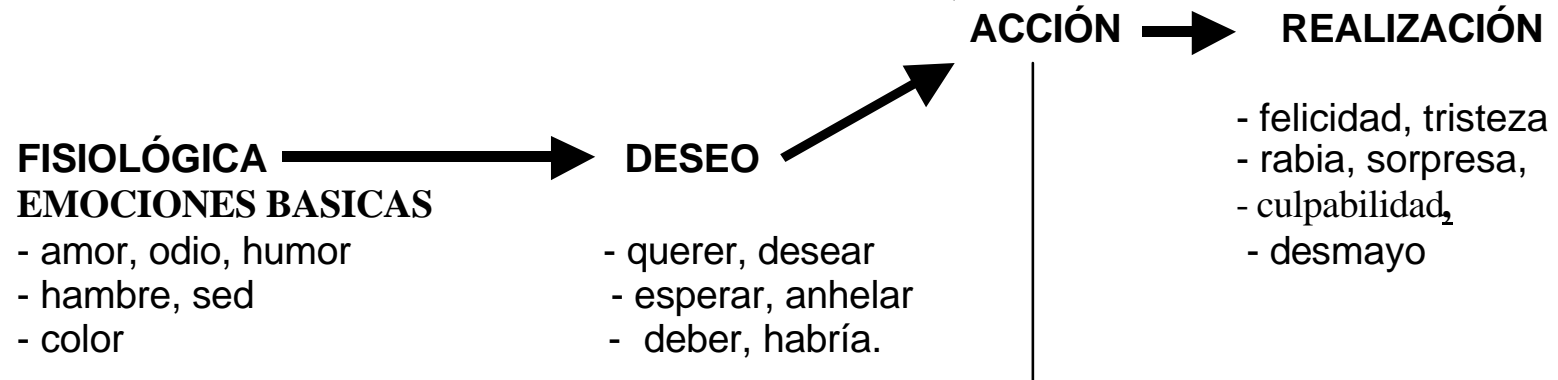




\section{GRÁFICO 2}

Esquema elaborado para describir el razonamiento de la creencia-deseo.

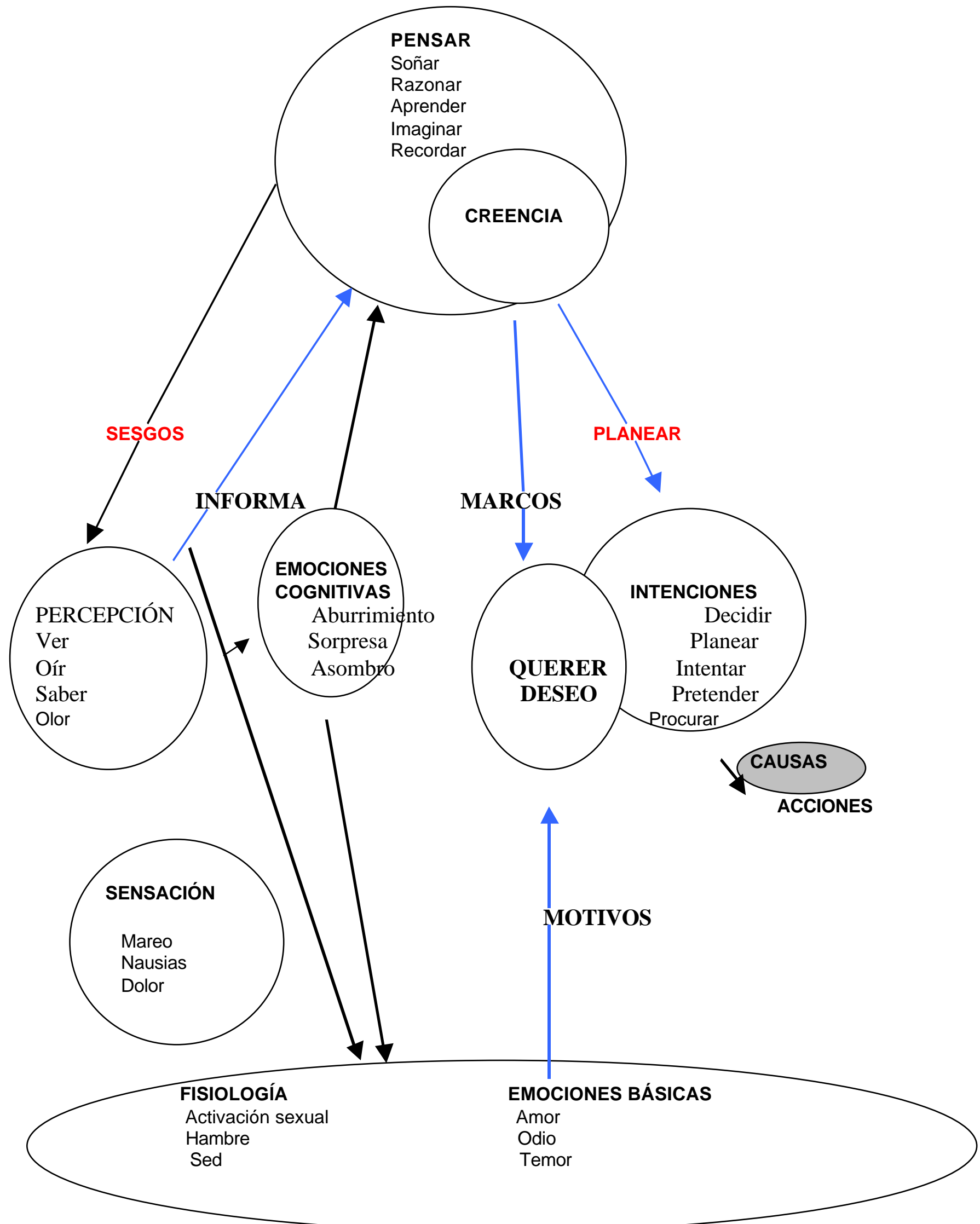


Es importante considerar que esta propuesta implica una verdadera integración de saberes, en un marco compartido y aceptado. Se requiere de una teoría general de la personalidad, como ya se nombró, para permitir la detección y orientar la categorización de rasgos y móviles que pueden pasar por imperceptibles e inexistentes ( véase Oliver Sacks ,1995). Sastre Vilarrasa y Moreno Marimon, escriben:

Eistein decía que la teoría es quien decide lo que nosotros podemos observar. También podría decirse que el sistema de enseñaza es quien decide lo que el alumnado puede saber. Ya que actuamos según nuestras creencias y convicciones, lo más importante es cambiar nuestras creencias y convicciones... (p. 41)

Advertir sobre esta propiedad de nuestros sistemas cognitivos frente al conocimiento, nos permite mirar con cuidado los antecedentes y concepciones previas, permitiendo ser conscientes de los sesgos que solapan el abordaje de los procesos afectivos-emocionales.

\section{PROCESOS AFECTIVOS-EMOCIONALES Y CAMBIOS DE CREENCIAS}

Para comprender los procesos afectivos-emocionales es necesario señalar el concepto de referencia social del que hablan Campos y Stenberg (1981), y que persisten en toda la vida adulta hasta incluso la senectud. La referencia social, circunscribe la actividad de los niños en la búsqueda del rostro de la madre para ser orientados, generando una teoría implícita de la emoción( Perner, p. 146) ${ }^{v}$. Esta actividad presupone un equipamiento innato del " significado ambiental " en las emociones ( $p$ 149), en contraposición a los modelos freudianos, por ejemplo. Esta confluencia va a constituir las primeras representaciones afectivo-emocionales comparadas con las emociones de fondo que denomina Damasio. Ya en el dominio nuclear ( Stern, D., 1977), se podría hablar de consciencia objetal, en donde los procesos afectivos -emocionales están aún indiferenciados y cuya resonancia en el si-mismo no posee aún un significado hasta la aparición del Sí-mismo subjetivo. La autoconsciencia ( Eccles, J.,1980, p. 69 ) permitirá el surgimiento de los sentimientos ${ }^{\mathrm{vi}}$ (Damasio, A. P 72) e interectuará con los procesos cognitivos superiores en la razón desarrollada del adulto. La predisposición a la interacción social ( Trevarthem, 1979; Stern, 1977) citados por Perner ( 1991) va a generar desde el interior del bebé los factores de actividad e interacción necesarios para el surgimiento de los modelos mentales múltiples. Estos son justamente los que van a posibilitar utilizar de modo integrado la información de las capacidades mentalistas del "Self" entre la percepción emocional y afectiva que desemboca en un desarrollo normal cumbre en la capacidad empátíca. Por lo tanto, aquí, a diferencia de los autores antes nombrados, se propone que esta capacidad es una consecuencia de una integración del adentro y del afuera posibilitado por los logros cognitivos del uso de los modelos múltiples ( Perner, J., p. 144). Esta capacidad no puede establecerse sin la capacidad de reciprocidad percibida nombrada anteriormente. Se estaría en aquello que Trevarthen ( 1979) ${ }^{\text {vii }}$ llama intersubjetividad secundaria . La empatía (Theodore Lipps, 1903), constituiría un termino clave para conceptualizar psicologógicamente estas capacidades que sostienen las relaciones entre las personas. Edith Stein en su trabajo El Problema de la Empatía en 1917, escribe:

Tratemos de la empatía misma. También aquí se trata de un acto que es originario como vivencia presente, pero no originario en su contenido. $Y$ este contenido es una vivencia que de nuevo puede presentarse en diversos modos de actuación, como recuerdo, espera, fantasía. Cuando aparece ante mí de golpe, está ante mí como objeto ( vg., la tristeza que " leo en la cara " a otros), ella ya no es objeto en sentido propio, sino que me ha transferido hacia dentro de sí; ya no estoy vuelto hacia ella, sino vuelto en 
ella hacia su objeto, estoy cabe su sujeto, en su lugar. Y sólo tras la clarificación lograda en ejecución, me hace frente otra vez la vivencia como objeto. (p.26)

La unidad de análisis a la que se hace referencia, es la del razonamiento de creencias-deseos, que fue presentada por primera vez por Wellman y Bartsch (1988). En un trabajo posterior Henrry H. Welleman (1990), escribe :

Habitualmente intentamos predecir y explicar lo que las personas hacen aludiendo a sus deseos, conocimientos, anhelos, conceptos erróneos, temores, expectativas y dudas. Estos constructos pueden dividirse a grosso modo en dos grupos complementarios: creencias ${ }^{\text {viii }} \ldots$ y deseos ${ }^{\text {ix }}$. Según esta teoría del sentido común, el recurso a estos dos tipos de conceptos nucleares es necesario si pretendemos ofrecer una explicación de las acciones intencionales.( p. 114) .

Otro eslabón que puede tomarse de este autor estriba en el ensamble con las teorías motivacionales en el trabajo de Joseph Nuttin (1980,1982) y Willy Lens $(1982,2003)$ sobre la importancia de los contenidos cognitivos en cuanto medio-fines en la estructuración del comportamiento.

Queda reflexionar sobre el esfuerzo que realizó Nuttin en el análisis e integración de los datos experimentales que se desprenden de una rigurosa aplicación del método y la naturaleza del objeto psicológico, que le llevan a establecer también comparaciones y contrastes entre otros autores de la Psicología del desarrollo como Perner ( 1988), Flavell (1988) y Gopnik (Forguson y Gopnik, 1988) y los temas de la adquisición del sentido básico de las representaciones mentales (Wellman, H., 1990. p 249). Estas disquisiciones tienen en común, de algún modo, la presencia del cuerpo ${ }^{x}$ y su importancia para el abordaje integral de los procesos cognitivos emocionales. Este presupuesto, en al ámbito de la Psicología, arrastra una concepción educativa nutrida en lineamientos acerca de las "condiciones" (Pozo, J,l; Schuer, N, 2001 ) del proceso de enseñanza y aprendizaje, alejándose de una interpretación carteciana del aprendizaje humano, al considerar la presencia y funciones del cuerpo como parte del sí-mismo.

\section{BIBLIOGRAFÍA}

BARREIRO, T. (1992) Trabajos en grupos. Buenos Aires: Kapeluz.

BELÁUSTEGUI. G. D. (2003) El modelo de Vygosky y el dualismo interaccionista. Una aproximación al estudios de las relaciones interfuncionales entre la conciencia,la afectividad y la imaginación. Curso: Enfoques socioculturales. Manuscripto en evaluación .

Castorina J. A; Faigenbaum G. (2002) The Epistemological Meaning of Constraints in the Development of Domain Knowledge. Theory \& "Psycology (2002) Vol 12 (3): 315-334.

DAMASIO, A.(1989). The Feeling of what Happens. (Trad.I cast. Por Pierre Jacomet: Sentir lo que sucede. Chile: Editorial Bello, 2000).

DAMASIO,A.(1994). Descartes's error. Emotion, reason and the human brain. New York: Avon Books. ( Trad. cast. De J. Ros: El error de Descartes. Barcelona: Crítica,1996).

ECCLES, J (1984). The Human Psyche. Springer-Verlag. ( Trad. Cast. García Trevijano, C ) La psique humana. Madrid: Tecnos, 1986. 
ECCLES, J, ZEIER, H.(1980). Gehirn and Geist. Munich: Kindler Verlag Gmbh. (Trad. Cast. Diorki). El cerebro y la mente. Barcelona: Herder, 1984.

FODOR, J. A (1983) The modularity of Mind. MIT Press. ( Trad. Castellana: La modularidad de la mente. Madrid: Alianza, 1994).

GARDNER, H.(1985). The Mind's News Science. A History of the Cognitive Revolution. N.Y: Basic Books. ( Trad. Cast. Wolfson, L). L a Nueva ciencia de la mente. Madrid: Piados, 1987.

(1993) Frames of Mind. The theory of multiple inteligens. N.Y: Basic Books. ( Trad. Cast. Wolfson, L) Estructura de la mente. La teoría de las inteligencias múltiples. Madrid: Fondo de cultura Económica.

GonzÁlez ReY, F. (2002) Sujeto y Subjetividad. Una aproximación histórico Cultural. México: Thomson.

Good, T.,BroPHY, J. (1995). Contemporary Educational Psycology. N.Y: Longman P. ( Trad. CAst. Velásquez Arellano, J.A) Psicología educativa. Contemporanea. (Quinta edición revisada) México: Mc GrawHill.,1997.

KAPLAN, L. J.A( 1995) Adolescense. The farewell to childhood. New York: Simon and Schuster. ( Trad. Cast. Vitale de, G. ) Adolescencia el adios a la infancia. ( 2da reipresión) Buenos Aires: Piados, 1996.

KARMILOFF-SMITH, A. (1992) Beyond Modularity. A Developmental Perspective on Cognitive Science. 8( Trad. Cast. Gomez Crespo, J. C. Núñez Bernardos, M. ) Más allá de la modularidad. La ciencia cognitiva desde la perspectiva del desarrollo. Madrid: Alianza Editorial, 1994.

MCKERNAN, J. ( 1996)Curriculumn Actino research.London: Kogan Page Limited. ( Trad. Cast. Amo, T.)Investigación- Acción y currículo. Métodos y recursos APRA profesionales reflexivos. Madrid: Morata, 1999.

NUTTIN, J. ( 1980). Théhoririe de la motivation humanine.Du besoin au projet dáction. París: presses Universitaires de France. ( Trad. Cast). Teoría de la motivación humana. Madrid: Paidós.

PETIT, F. (1979). Introduction a la psychologie des organisation. Toulouse: Privat Editeur. ( Trad. Cast. Llopis, J. ) Psicosociología de las organizaciones. Barcelona: Herder,1984.

PERNER, J. (1991). Understanding the representational mind. Massachustts: The Massachusetts Institute of Technology. ( Trad. Cast. Galmarini, M. A ) Comprender la mente reprsentacional. Madrid: Piados, 1992.

POPPER, K.R, ECCLES, J.C.M (1977). The self ant its brain. Berlin, Heidelberg, N. Y: SpringgerVerlag . ( Trad. Cast.Solís, S. ) El YO y su Cerebro. Barcelona: Labro Universitaria, 1980.

PozO, J.I. (2001). Humana mente. El mundo, la conciencia y la carne. Madrid: Morata.

SASTRE VILARRASA, G; MARIMON MORENO, M. (2002) resolución de conflictos y aprendizaje emocional. Una perspectiva de género. Barcelona:España.

RosSelló I MIR, J.(1997) Psicología de la atención. Introducción al estudio del mecanismo atencional. Madrid: Pirámide. 
SACKS, O. (1995). Escotoma: Una historia de olvido y desprecio científico. En: Sacks, O.; Kevles, D.J.; Lewontin, R. C.; Jaay Gould, S.; Miller, J. Hideen Histories of Science. NY: NYREV. ( Trad. Cast. Martínez Muñoz, C. ) Historias de la ciencia y del olvido. Madrid: Siruela, 1996.

SCheuer, N; Pozo, J.I; De LA CrUZ, M.; BacalLÁ, N. (2001). Cómo aprendí a dibujar? Las teorías de los niños sobre el aprendizaje. Estudios de Psicología, 2001,22 (1), 185-205.

SHELDRAKE, R.(1988). The present of the past. London: Blond and Briggs. ( Trad. Cast. Coronado, M.) .La presencia del pasado. Resancia mórfica y hábitos de la naturaleza. Kairós: Barcelon, 1990.

SPERBER, D. (1994). La modularidad del pensamiento y la epistemología de las representaciones. En mapping the Mind. Domain Specificity in Cognition and Culture. Hirschfeld L.A. and Gelman S. A. Cambridge: Cambridge University Press. ( Trad. Cast. Ruia, A. ) Cartografía de la mente. La especificidad de dominio en la cognición y en la cultura. Volumen I. Orígenes, procesos y conceptos. Madrid: Gedisa, 2002.

STEIN, E. ( 1917). Zum Problem der Einfühlung. Múnchen: Verlagsgeselllschaft Gerhard Kaffke mbH. ( Trad. Cast. Caballero Bono, J. L.). El Problema de la empatía. Madrid: Trotta, 2004.

STERN, D. (1985). The Interpersonal World of the Infant. A View from Psychoanalysis and Devellopmental Psychology. N.Y: Basisc Books. ( Trad. Cast.Piatigorky, J) El mundo interpersonal del infante. . Buenos Aires: Piados, 1990.

STENBERG, R. S. ( 1982). Handbook of Human Inteligence. Cambridge: Cambridge Universty Press. ( trad. Cast. Rosenbaum, D.) Inteligencia Humana, cognición, personalidad e inteligencia. Tomo I,II,III,IV. (Primera Edición) España: . Piados,1987.

RIVIÈRE, A.;NUÑEZ, M.(1996) La Mirada Mental. Aique: Buenos Aires.

RIVIÈRE, A., ESPAÑOL, S. (1990) Comunicazione, sospensione e semiosi umana:le origini della pratica e della compresione Enterpersonali. Ricerche di sociología e psicología della cominizazione, 1, 4576. La suspensión como mecanismo de creación semiótica.

\section{Anexo}

Actividad no 2.

Expresión oral de conflictos interpersonales.

\section{Objetivos}

- Dar al alumnado la oportunidad de expresar sus ideas en relación a los conflictos y de contrastarlas con las de las demás personas de la clase.

. ofrecer al profesorado una primera aproximación a las ideas del alumnado en relación a los conflictos.

Indicaciones metodológicas

Esta actividad, como el resto de las que configuran el tema, se basa en una concepción del conflicto como un proceso que se desarrolla en el tiempo y que consta d diferentes fases: 
A) Podemos hablar, en primer lugar, de una situación inicial conflictiva. Es el momento en que el conflicto se manifiesta. Es la fase que nos permite identificarlo, enterarnos de que existe un problema de relación.

B) Todo conflicto manifiesto tiene un por qué, una historia anterior en la que se localizan sus causas. Es la fase de los antecedentes, aquella que explica el conflicto y que es necesario reconstruir para entenderlo.

C) Hablamos de tercera fase cuando nos referimos al momento de las soluciones. Unas soluciones que calificamos de adecuadas cuando no son violentas ni sexistas ni racistas, cuando son justas y cuando no son arbitrarias e inciden sobre las causas del conflicto, contrarrestándolas e eliminándolas.

D) Si las soluciones imaginadas son adecuadas, la situación inicial conflictiva se transforma en una situación final no conflictiva. Es la última fase en un proceso de desarrollo óptimo. Si no son adecuadas, el conflicto persiste, ya sea de forma evidente o soterrada.

El siguiente esquema ilustra el conflicto como proceso con fases que se suceden:

\begin{tabular}{|c|c|c|c|c|}
\hline $\begin{array}{l}\text { Antecedentes } \longrightarrow \\
\text { Del conflicto } \\
\text {-causas- }\end{array}$ & $\begin{array}{l}\text { Situación inicial } \\
\text { conflictiva }\end{array}$ & $\rightarrow$ & $\begin{array}{l}\text { Soluciones } \\
\text { adecuadas }\end{array}$ & $\begin{array}{l}\rightarrow \text { Situación } \\
\text { conflic. }\end{array}$ \\
\hline & & & $\begin{array}{l}\text { Soluciones } \\
\text { Inadecuadas }\end{array}$ & $\begin{array}{l}\rightarrow \text { Persiste } \\
\text { s el conflic. }\end{array}$ \\
\hline
\end{tabular}

a) Con el alumnado de infantil y primeros cursos de primaria

Se puede iniciar la actividad cogiendo dos marionetas y representa y representando un conflicto entre ellas, a la vista de todas las personas de la clase. Poder atribuir problemas personales a las marionetas ayuda, a las niñas y niños, a expresar ideas y sentimientos que pueden resultarles difíciles de abordar directamente.

Dado que se trata de una actividad de evaluación inicial, en la que se pretende conocer qué tipo de dificultades tienen cuando se trata de analizar y dar respuesta a un conflicto, es fundamental que la persona adulta se abstenga de proporcionar modelos. Se limitará a representar, con las marionetas, la manifestación del conflicto -pelearse, discutir, gritarse, enfadarse, etcétera-., sin hacer ninguna referencia a su historia ni alas posibles soluciones.

A partir de las representación que la profesora o el profesor hace del conflicto, se le pide que imaginen y expliquen historias en las que los personajes acaben peleados entre ellos - 0 enfadados 0 discutiendo-. Tras el relato espontáneo de cada historia, se les invita a buscar manera de que los personajes resuelvan el problema que tienen.

Interesa que se expliciten sus ideas sin que les coaccione lo moralmente adecuado. Por esta razón, y en este momento de la evaluación inicial, el profesorado se abstendrá de intervenir, sean cuáles fueren las 
soluciones que propongan. Conviene prestar atención a que, tanto ellas como ellos, relaten historias y que no sean excesivamente largas ni estén desvinculadas de su entorno humano.

En el caso de no disponer de marionetas se pueden utilizar dibujos que representen conflictos similares al de la lámina número 6 ( ver anexo), explicándoles que los han hecho niñas y niños de su misma edad para hablar de algunos de sus problemas habituales. A la vista del dibujo se les incita a imaginar y explicar historias en la que surjan problemas entre los personajes dibujados, y a acompañar cada historia de las maneras cómo los protagonistas has resulto las desavenencias.

\section{Notas}

\footnotetext{
¿ Una discriminación importante es la diferencia entre el afecto y la emoción (MacLean, P.D., 1970)que cita John Eccles en La Psique Humana ( p.180).

ii La tesis fundamental - que esbozamos a grandes rasgos - afirma que, en el punto de partida, el estado motivacional pone en marcha no sólo el sistema perceptual y motor, sino también el funcionamiento cognitivo completo del individuo. (p 149

iii Este mismo autor profundiza sobre estas modalidades de contacto a partir de sus investigaciones empíricas, estableciendo que el movimiento "hacia el objeto" es una de las dos orientaciones dinámicas de la conducta, va a diferenciarse según variables que van a organizarse a partir de la naturaleza del objeto contactado como también del proceso que se encuentra afectando la motivación. Las primeras reconoce como la necesidad sexual y eróticaii, las cuales agrega otras tres modalidades: el afecto, la consideración y determinadas formas de ayuda y cooperación. Esta pueden alcanzar el altruismo si hay una preocupación real por parte del sujeto pero además reconoce que hay dos tipos de relación negativa: una donde se estable la defensa y la otra donde el sujeto desea causar daño.

iv Al modo de la analogía utilizada por Lawrence A. Hirschfeld.

${ }^{\vee}$ Perner mismo cuestiona este tipo de denominación.

vi Patrones sensoriales señalan dolor o placer. Las emociones se transforman en imágenes.

${ }^{\text {vii }}$ Podría relacionarse con el concepto de Espacio transicional de Donald Winnicott.

viii Entendidas en sentido amplio como aquellos constructos que influyen en el conocimiento, en las convicciones, suposiciones, ideas y opiniones del actor.

${ }^{i x}$ Entendidos en sentido amplio como constructos que inf luyen en todas las actitudes a favor y en contra de un actor, tales como los deseos, anhelos, preferencias, metas y aspiraciones, a I igual que las obligaciones y valores y aspiraciones auto impuestas.

${ }^{x}$ En térmnos de Grardner: ...el cuerpo es más que tan sólo otra máquina, indistinguible de los objetos artificiales del mundo. También es la vasija del sentido del yo del individuo, de sus sentimientos y aspiraciones más personales, al igual que la entidad a la que otros responden en una manera especial debido a sus cualidades singularmente humanas. Desde el mero principio, la existencia de un individuo como ser humano afecta la manera en que otros lo tratarán, y muy pronto el individuo llega a pensar que su cuerpo se especial. Llega a formarse un sentido del yo que modificará en forma perpetua, y que a su vez influenciará en sus pensamientos y conducta a medida que responde a otros en su ambiente en términos de sus rasgos distintivos y conductas. ( p. 285)
} 


\title{
Contactar
}

Revista lberoamericana de Educación

\author{
Principal OEI
}

